Research Paper

\title{
Impact of remote ischaemic preconditioning on cerebral oxygenation during total knee arthroplasty
}

\author{
Chung-Sik Oh${ }^{1}$, Seong-Hyop Kim¹,2, Jaemoon Lee ${ }^{1}$, Ka Young Rhee ${ }^{1,2} \bowtie$ \\ 1. Department of Anaesthesiology and Pain Medicine, Konkuk University Medical Centre, Konkuk University School of Medicine, Seoul, Korea; \\ 2. Research Institute of Medical Science, Konkuk University School of Medicine, Seoul, Korea. \\ $\triangle$ Corresponding author: Ka Young Rhee, M.D., Ph.D., Department of Anaesthesiology and Pain Medicine, Konkuk University Medical Centre, 120-1 \\ Neungdong-ro, Gwangjin-gu, Seoul, 05030, Republic of Korea. Tel: +82-2-2030-5446 Fax: +82-2-2030-5449 E-mail: rheeky@kuh.ac.kr. \\ (c) Ivyspring International Publisher. This is an open access article distributed under the terms of the Creative Commons Attribution (CC BY-NC) license \\ (https://creativecommons.org/licenses/by-nc/4.0/). See http://ivyspring.com/terms for full terms and conditions.
}

Received: 2016.08.16; Accepted: 2016.12.21; Published: 2017.02.07

\begin{abstract}
Background: Ischaemic reperfusion injury (IRI) after tourniquet release during total knee arthroplasty (TKR) is related to postoperative cerebral complications. Remote ischaemic preconditioning (RIPC) is known to minimise IRI in previous studies. Thus, we evaluated the effect of RIPC on regional cerebral oxygenation after tourniquet release during TKR.

Methods: Patients undergoing TKR were randomly allocated to not receive RIPC (control group) and to receive RIPC (RIPC group). Regional cerebral oxygenation and pulmonary oxygenation were assessed up to $24 \mathrm{~h}$ postoperatively. The changes in serum cytokine and lactate dehydrogenase (LDH) levels were assessed and arterial blood gas analysis was performed. Total transfusion amounts and postoperative bleeding were also examined.

Results: In total, 72 patients were included in the final analysis. Regional cerebral oxygenation ( $P$ $<0.001$ in the left side, $P=0.003$ in the right side) with pulmonary oxygenation $(P=0.001)$ was significantly higher in the RIPC group. The serum LDH was significantly lower in the RIPC group at $1 \mathrm{~h}$ and $24 \mathrm{~h}$ postoperatively $(\mathrm{P}<0.001)$. The $24 \mathrm{~h}$ postoperative transfusion $(\mathrm{P}=0.002)$ and bleeding amount $(\mathrm{P}<0.001)$ were significantly lower in the RIPC group.

Conclusions: RIPC increased cerebral oxygenation after tourniquet release during TKR by improving pulmonary oxygenation. Additionally, RIPC decreased the transfusion and bleeding amount with the serum LDH level.
\end{abstract}

Key words: Cerebral oxygenation, Ischaemic reperfusion injury, Remote ischaemic preconditioning, Total knee arthroplasty.

\section{Introduction}

Total knee arthroplasty (TKR) is a common major surgical procedure in the elderly, and the number of elderly patients undergoing TKR is increasing [1]. Tourniquet release during the late period of TKR can induce ischaemic-reperfusion injury, eliciting the activation of neutrophils, circulating pro-inflammatory cytokines, and reactive oxygen species [2, 3]. As a result, transient hypotension and acidosis can occur [4,5], and serious cerebral complications can be induced $[3,6,7]$. Therefore, efforts to minimise these complications can be crucial to anaesthesiologists.

Ischaemic preconditioning describes the phenomenon where transient and brief ischaemia confers protection against a subsequent prolonged and injurious period of ischaemia. Considering that tourniquet application during TKR is related to ischaemic injury, the organ protective effect of ischaemic preconditioning can have a beneficial role after tourniquet release during TKR. However, it is not easy to apply ischaemic preconditioning in a clinical setting because brief organ ischaemia should be preceded after real ischaemic time [8]. Meanwhile, the organ protective effect of ischaemic preconditioning could be induced when the episodic ischaemia is at distant tissues or organs, the concept 
being termed remote ischaemic preconditioning (RIPC) [9]. The application of RIPC into clinical fields is more useful than ischaemic preconditioning because it is easy to apply briefly preceding ischaemia to distant organs such as the limbs. Therefore, RIPC can be used as a strategy of organ protection $[9,10]$.

Many clinical trials have been conducted and have shown that RIPC has potential clinical benefits $[8,11]$. However, most of the studies on RIPC have been conducted only in the heart or kidney models in animals [9, 10, 12-14], and few studies have evaluated the beneficial effect of RIPC during TKR.

Therefore, we hypothesised that RIPC would show the protective effect of hypoperfusion insult on the brain in patients undergoing TKR. The study was designed to evaluate the organ protective effect of RIPC, especially in the brain, in patients undergoing TKR.

\section{Methods}

\section{Study population}

After obtaining approval from the Institutional Review Board (KUH 1160078; granted by the Institutional Review Board of Konkuk University Medical Centre, Seoul, Korea) and informed consent from patients, the study was registered at www.clinicaltrial.gov. (NCT02478216). Patients undergoing TKR were enrolled. Exclusion criteria included the following: 1) emergency operation, 2) underlying neurologic disorder, 3) underlying peripheral vascular disease, and 4) other types of concurrent surgery.

The patients were allocated randomly to not receive remote preconditioning (Control) or to receive remote preconditioning (RIPC) using sealed envelopes, with the options inside the sealed envelope of $C$ and $R$ before anaesthesia induction. A registered nurse who did not participate in patient care and was blind to the study performed all of the randomisation processes. All of the medical staff involved in the patient care was blind to the study. All of the data were collected by trained observers who were blind to the study and did not participate in the patient care.

\section{Anaesthetic regimen}

The anaesthetic technique was standardised. The patient arrived at the operation room without premedication. After establishing routine patient monitoring [pulse oximetry, electrocardiography, non-invasive blood pressure monitoring, near infra-red spectroscopy and bispectral index (BIS)] and radial artery cannulation on the opposite side of the operation for invasive systemic arterial blood pressure monitoring and sampling, anaesthesia was induced. The transducer for invasive systemic arterial blood pressure monitoring was positioned at the mid-axillary level in the supine position. The anaesthesiologists, blind to the study, were requested to anaesthetise the patients as below. Thiopental sodium $5 \mathrm{mg} / \mathrm{kg}$ was intravenously administered for anaesthesia induction. Remifentanil $5 \mathrm{ng} / \mathrm{ml}$ for plasma target concentration was intravenously administered and maintained until the end of surgery using target-controlled infusion (TCI Orchestra ${ }^{\circledR}$ Base Primea, Fresenius Vial, Brezins, France). Rocuronium $0.6 \mathrm{mg} / \mathrm{kg}$ was intravenously administered for muscle relaxation after the loss of consciousness under the guidance of peripheral neuromuscular transmission (NMT) monitoring. Tracheal intubation was performed at the train-of-four count of 0 . Anaesthesia was maintained with sevoflurane and was titrated to maintain BIS values between 40 and 60 . After anaesthesia induction, the patients were ventilated with $40 \%$ oxygen in air. The tidal volume was $6 \mathrm{~mL} / \mathrm{kg}$ (lean body mass), and positive-end expiratory pressure was not utilised. The respiratory rate was adjusted to keep the partial pressure of end-tidal carbon dioxide between 35 and $40 \mathrm{mmHg}$. Additional rocuronium was administered under the guidance of the peripheral monitoring of NMT. During anaesthesia, phenylephrine $30 \mu \mathrm{g}$ [if the systemic mean arterial blood pressure (MBP) was below $60 \mathrm{mmHg}$ and the heart rate (HR) was above 40 beats/min], ephedrine $4 \mathrm{mg}$ (if MBP was below 60 $\mathrm{mmHg}$ and HR was below 40 beats/min) or atropine $0.5 \mathrm{mg}$ (if $\mathrm{HR}$ was below 40 beats $/ \mathrm{min}$ ) was intravenously administered to prevent hypotension or bradycardia. Phenylephrine was continuously infused if the MBP was below $60 \mathrm{mmHg}$ and was continued with repetitive phenylephrine injections. Sevoflurane and TCI of remifentanil were stopped at the end of surgery. Residual neuromuscular paralysis was antagonised with sugammadex $2 \mathrm{mg} / \mathrm{kg}$ under the guidance of peripheral NMT monitoring. After tracheal extubation, the patient was transferred to the postanaesthetic care unit (PACU).

\section{Remote ischaemic preconditioning (RIPC)}

RIPC was performed just after anaesthesia induction and before tourniquet application for the operation site. The tourniquets were applied at both thighs in all of the patients. The thighs were covered with a blanket to conceal the tourniquet inflation and deflation. For the control group, the tourniquet was applied with an inflation pressure of $0 \mathrm{mmHg}$. For the RIPC group, three cycles of tourniquet inflation at the opposite thigh from the operation for 5 minutes with double systemic systolic arterial blood pressure on arrival at the operation room and deflation were performed. The tourniquet pressure according to the 
randomisation was set by the registered nurse who participated in the patients' allocation.

\section{Measurements}

The changes in MBP and HR were checked during the perioperative period. Regional cerebral oxygenation saturation $\left(\mathrm{rScO}_{2}\right)$ in the left and right sides were checked at the following times: before anaesthesia induction (Preop), just before application of the tourniquet for the operation site (Pre TQ), just after the application of the tourniquet for the operation site (Start TQ), just before the release of the tourniquet for the operation site (End TQ), just after the release of the tourniquet for the operation site (TQ release), and $1 \mathrm{~h}$ postoperatively (Post $1 \mathrm{~h}$ ).

Arterial blood gas analyses (ABGA) were performed to check the arterial carbon dioxide partial pressure $\left(\mathrm{PaCO}_{2}\right)$; the ratio of the arterial oxygen partial pressure to the fractional inspired oxygen (PF ratio); haematocrit (Hct); and lactate at Preop, End $\mathrm{TQ}$, and TQ release. Laboratory data, including the levels of creatinine phosphokinase (CPK), lactate dehydrogenase (LDH), aspartate aminotransferase (AST), and creatinine $(\mathrm{Cr})$, were also checked at Preop, postoperative $6 \mathrm{~h}$ (Post $6 \mathrm{~h}$ ), and postoperative $24 \mathrm{~h}$ (Post $24 \mathrm{~h}$ ).

Transfusion with packed red blood cells (pRBCs) was performed when the Hct was below 30\% in the operation room and general ward during the pre- and post-operative periods. The postoperative bleeding amount was checked over the following $24 \mathrm{~h}$ period with a hemovac.

The anaesthesia time (from the administration of thiopental sodium to discharge from the operation room) and operation time (from the skin incision to dressing) were recorded.

The incidence of postoperative cognitive dysfunction (POCD) using the confusion assessment method (CAM) scores [15, 16] was checked by a neurologist up to postoperative day 7 .

\section{Cytokines}

Secreted cytokines were measured by enzyme-linked immunosorbent assay (ELISA) kits (R\&D systems, Minneapolis, MN, USA). Blood samples were centrifuged at 3,000 rpm at $5 \mathrm{~min}$, and the serum levels of pro-inflammatory cytokines such as interleukin (IL)- 6 and tumour necrosis factor- $\alpha$ (TNF- $\alpha$ ), as well as anti-inflammatory cytokines such as IL-10 and transforming growth factor- $\beta$ (TGF- $\beta$ ), were measured at Preop, End TQ, Post 1 h, Post 6 h, and Post $24 \mathrm{~h}$.

\section{Statistics}

The primary outcome was the difference in $\mathrm{rScO}_{2}$ between the control and RIPC groups. A priori power analysis yielded a partial $\eta^{2}$ of 0.0 .301 and an effect size of 0.656 in the left side $\mathrm{rScO}_{2}$ and a partial $\eta^{2}$ of 0.0.140 and an effect size of 0.5465 in the right side $\mathrm{rScO}_{2}$ in the values were calculated from our pilot study data. The calculated sample size for the primary outcome was 28 in each group for left-side $\mathrm{rScO}_{2}$ and 36 in each group for right-side $\mathrm{rScO}_{2}$ with an a value of 0.05 and power of 0.8 . Therefore, we set 36 patients in each group; a total of 86 patients were enrolled in our study with a dropout rate of $20 \%$.

Normally distributed continuous data were presented as the mean \pm standard deviation (SD). Continuous data, which were not distributed normally, were presented as the median $(25 \%-75 \%)$. To compare intergroup differences between the RIPC and control groups, Student's t-test or the Mann-Whitney U-test was performed according to the normal distribution. For categorical variables, the chi-squared test was used. Intergroup differences over time were analysed by two-way analysis of variance for repeated measures and, if significant, Bonferroni's correction was performed for multiple comparisons. Statistical analysis was performed using the Statistical Package for the Social Sciences software $18^{\circledR}$ (IBM SPSS Inc., Chicago, IL, USA). A P-value less than 0.05 indicated statistical significance.

\section{Results}

In total, 86 patients were eligible for the study from February 2015 to May 2016. Fourteen patients were excluded for the following reasons: six patients with an emergency operation, three patients with an underlying neurologic disorder, two patients with underlying peripheral vascular disease, and three patients with other types of concurrent surgery. Therefore, 72 patients were included in the final analysis (Figure 1).

The distribution of patient demographic variables was similar between the two groups (Table 1). The postoperative $24 \mathrm{~h}$ transfusion and bleeding amount were significantly lower in the RIPC group (Table 1). Postoperative cognitive dysfunction was not detected in all cases. MBP did not show a significant intergroup difference (Fig 1A); however, the HR was significantly higher in the RIPC group $(\mathrm{P}=0.036)$ (Fig 2B).

The $\mathrm{rScO}_{2}$ in the left side was significantly higher in the RIPC group at TQ release $(\mathrm{P}<0.001)$ (Fig 2C), and the $\mathrm{rScO}_{2}$ in the right side was significantly higher in the RIPC group at Post $1 \mathrm{~h}(\mathrm{P}=0.003)$ (Fig 2D).

In the result of $A B G A$, the $\mathrm{PF}$ ratio was significantly higher in the RIPC group at TQ release ( $P$ $=0.001$ ) (Fig 3A); however, $\mathrm{PaCO}_{2}$, Hct, and lactate did not differ between the groups (Table 2). The 
serum LDH level was significantly lower in the RIPC group at Post $1 \mathrm{~h}$ and $24 \mathrm{~h}(\mathrm{P}<0.001)$ (Fig 3B). Other laboratory data and the serum cytokine levels did not differ between the groups (Tables 3 and 4).

Table 1. Demographic data.

\begin{tabular}{|c|c|c|c|}
\hline & Control $(\mathrm{N}=36)$ & $\operatorname{RIPC}(\mathrm{N}=36)$ & $P$ \\
\hline Gender & & & 0.199 \\
\hline Male & $31(47.0 \%)$ & $35(53.0 \%)$ & \\
\hline Female & $5(83.3 \%)$ & $1(16.7 \%)$ & \\
\hline Age (years) & $71.4 \pm 7.2$ & $69.1 \pm 6.6$ & 0.163 \\
\hline Height (cm) & $152.0(148.5-157.4)$ & $150.9(148.0-158.0)$ & 0.991 \\
\hline Weight (kg) & $61.1(54.5-67.6)$ & $56.5(51.2-62.1)$ & 0.075 \\
\hline Smoking history & $3(75.0 \%)$ & $1(25.0 \%)$ & 0.614 \\
\hline Operation site & & & 0.810 \\
\hline Left & $22(51.2 \%)$ & $21(48.8 \%)$ & \\
\hline Right & $14(48.3 \%)$ & $15(51.7 \%)$ & \\
\hline \multicolumn{4}{|l|}{ Underlying diseases } \\
\hline HTN & $21(53.8 \%)$ & $18(46.2 \%)$ & 0.478 \\
\hline $\mathrm{DM}$ & $11(52.4 \%)$ & $10(47.6 \%)$ & 0.795 \\
\hline \multicolumn{4}{|l|}{ Anaesthetic agents } \\
\hline Sevofluranemin (Vol\%) & $1.0(1.0-1.2)$ & $1.1(1.0-1.3)$ & 0.185 \\
\hline Sevoflurane $\max \left(V_{01} \%\right)$ & $2.0(1.8-2.0)$ & $1.8(1.5-2.0)$ & 0.217 \\
\hline Remifentanil $(\mu \mathrm{g})$ & $1408.0(1254.0-1755.5)$ & $1431.0(1276.0-1667.0)$ & 0.973 \\
\hline \multicolumn{4}{|l|}{ Vasopressor or inotropics } \\
\hline Phenylephrine $(\mu \mathrm{g})$ & $372.5(95.0-907.5)$ & $172.5(15.0-710.0)$ & 0.153 \\
\hline Ephedrine (mg) & $0.0(0.0-0.0)$ & $0.0(0.0-4.0)$ & 0.365 \\
\hline Incidence of atropine & $4(11.1 \%)$ & $6(16.7 \%)$ & 0.733 \\
\hline \multirow[t]{2}{*}{ Anaesthesia duration (min) } & & & 0.727 \\
\hline & $169.5(153.0-192.5)$ & $173.5(157.5-190.0)$ & \\
\hline \multirow{2}{*}{ Operation duration (min) } & & & 0.933 \\
\hline & $107.0(97.0-130.0)$ & $113.0(100.0-130.0)$ & \\
\hline \multirow{2}{*}{ Tourniquet duration (min) } & & & 0.000 \\
\hline & $0.0(0.0-0.0)$ & $300.0(280.0-300.0)$ & \\
\hline \multicolumn{4}{|l|}{ Transfusion and bleeding } \\
\hline \multicolumn{3}{|l|}{ Intraoperative $\mathrm{pRBC}$ transfusion (units) } & 0.043 \\
\hline 0 & $25(42.4 \%)$ & $34(57.6 \%)$ & \\
\hline 1 & $3(100.0 \%)$ & $0(0.0 \%)$ & \\
\hline 2 & $7(77.8 \%)$ & $2(22.2 \%)$ & \\
\hline 4 & $1(100.0 \%)$ & $0(0.0 \%)$ & \\
\hline \multicolumn{3}{|l|}{ Postoperative pRBC transfusion (units) } & 0.002 \\
\hline 0 & $25(41.0 \%)$ & $36(59.0 \%)$ & \\
\hline 1 & $1(100.0 \%)$ & $0(0.0 \%)$ & \\
\hline 2 & $10(100.0 \%)$ & $0(0.0 \%)$ & \\
\hline \multirow[t]{2}{*}{ Postoperative $24 \mathrm{~h}$ bleeding (mL) } & & & 0.000 \\
\hline & $365.3 \pm 192.2$ & $193.4 \pm 146.1$ & \\
\hline
\end{tabular}

Values are expressed as the number of patients or mean \pm standard deviation or median $(25 \%-75 \%)$.

Abbreviations: Control, control group; RIPC, remote ischaemic preconditioning group; HTN, hypertension; DM, diabetes mellitus; Sevoflurane min, $_{\text {, consumed minimal }}$

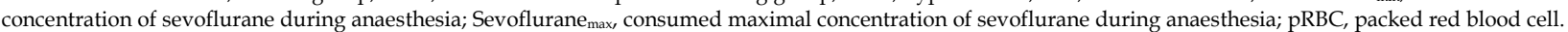

Table 2. Data from arterial blood gas analysis during total knee arthroplasty.

\begin{tabular}{lllll}
\hline & & Control $(\mathrm{N}=36)$ & RIPC (N =36) & \\
\hline PaCO $_{2}$ & & & $35.2 \pm 2.9$ & 0.315 \\
& & $34.5 \pm 2.7$ & $36.6(35.5-39.2)$ & 0.892 \\
& Preop & $37.0(35.7-38.5)$ & $43.8 \pm 3.9$ & 0.628 \\
Hct & TQ release & $43.4 \pm 4.0$ & $37 \pm 4$ & 0.584 \\
& & & $34 \pm 3$ & 0.480 \\
& Preop & $36 \pm 4$ & $34 \pm 3$ & 0.512 \\
Lactate & End TQ & $33 \pm 4$ & & $0.97(0.6-0.9)$ \\
& TQ release & $33 \pm 5$ & $1.1(0.8-1.3)$ & 0.239 \\
& & & $1.9(1.4-2.5)$ & 0.720 \\
& Preop & $0.8(0.7-0.9)$ & $0.8(0.7-1.1)$ & \\
\hline
\end{tabular}

Values are expressed as the number of patients or mean \pm standard deviation or median $(25 \%-75 \%)$.

Abbreviations: Control, control group; RIPC, remote ischaemic preconditioning group; $\mathrm{PaCO}_{2}$, arterial carbon dioxide partial pressure; Hct, haematocrit; Preop, before anaesthesia induction; Pre TQ, just before application of the tourniquet for the operation site;

End TQ, just before the release of the tourniquet for the operation site; TQ release, just after the release of the tourniquet for the operation site. 


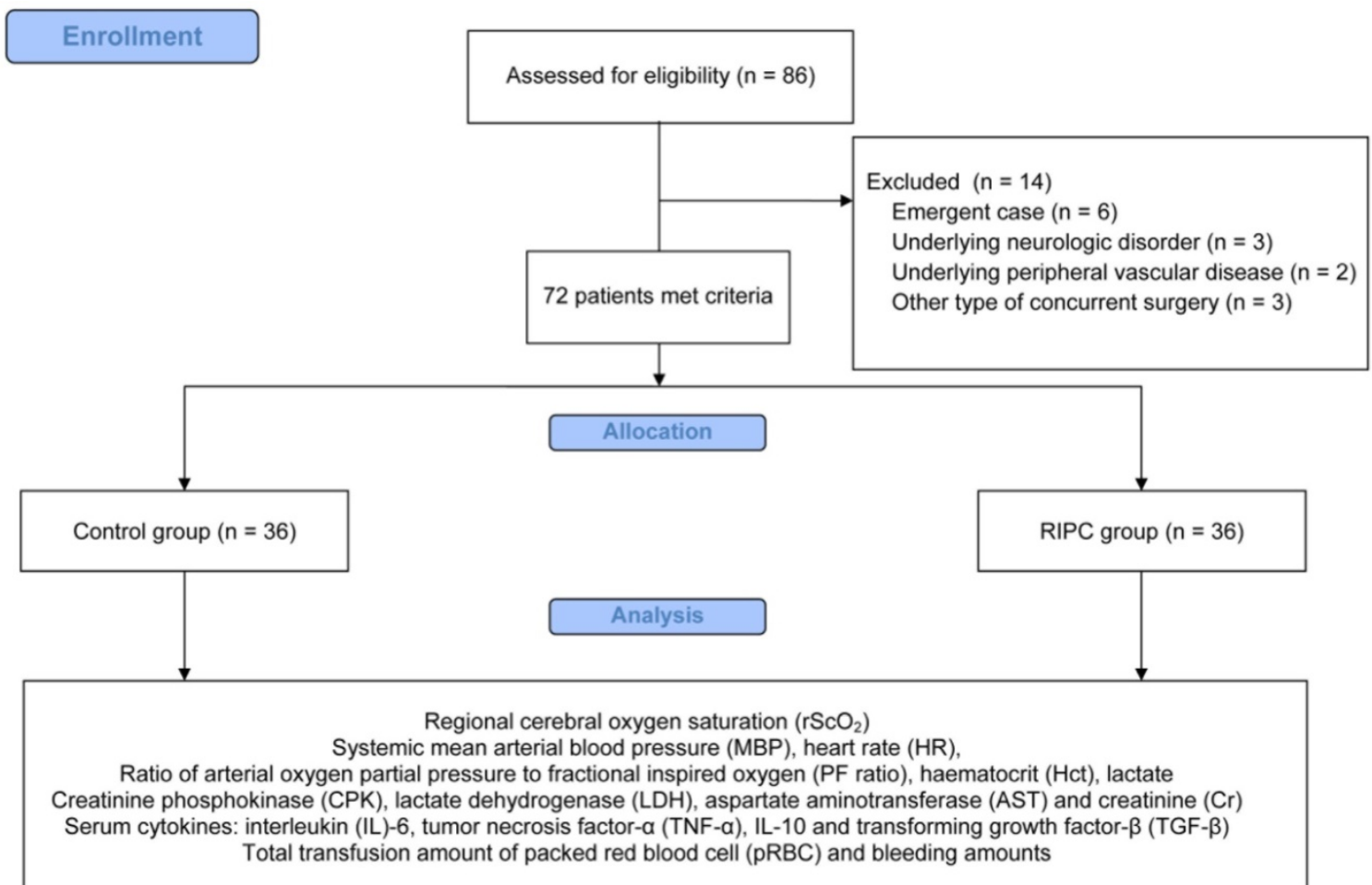

Figure 1. CONSORT flow diagram for the study.
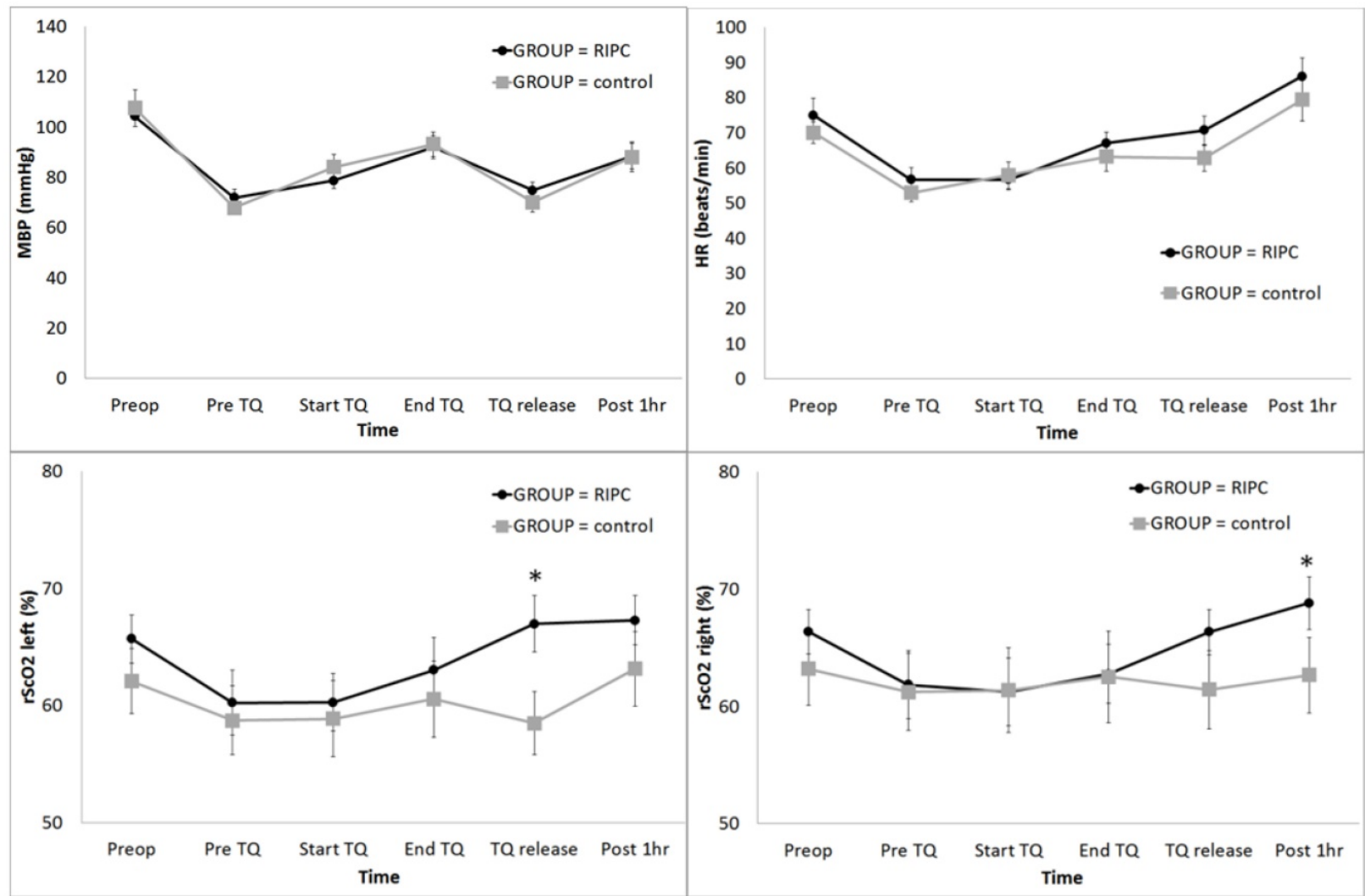

Figure 2. Change in the haemodynamic parameters and regional cerebral oxygen saturation $\left(\mathrm{rScO}_{2}\right)$ during total knee arthroplasty: (A) MBP, (B) $\mathrm{HR}$, (C) $\mathrm{rSCO}_{2}$ left, and (D) $\mathrm{rScO}_{2}$ right. Abbreviations: MBP, systemic mean arterial blood pressure; HR, heart rate; Lt, left; Rt, right; Preop, before anaesthesia induction; Pre TQ, just before the application of the tourniquet for the operation site; Start TQ, just after the application of the tourniquet for the operation site; End TQ, just before the release of the tourniquet for the operation site; TQ release, just after the release of the tourniquet for the operation site; Post 1 h, postoperative 1 h. * Adjusted by Bonferroni's correction. 
Table 3. Laboratory data during total knee arthroplasty.

\begin{tabular}{|c|c|c|c|c|}
\hline & & Control $(\mathrm{N}=36)$ & $\operatorname{RIPC}(\mathrm{N}=36)$ & $P$ \\
\hline \multicolumn{5}{|l|}{ CPK } \\
\hline & Preop & $78 \pm 27$ & $67 \pm 20$ & 0.054 \\
\hline & Post $1 \mathrm{~h}$ & $88 \pm 31$ & $85 \pm 24$ & 0.617 \\
\hline & $\begin{array}{l}\text { Post } 24 \\
\mathrm{~h}\end{array}$ & $143(94-244)$ & $188(134-271)$ & 0.130 \\
\hline \multicolumn{5}{|l|}{ AST } \\
\hline & Preop & $24(21-29)$ & $22(20-25)$ & 0.061 \\
\hline & Post $1 \mathrm{~h}$ & $25(20-30)$ & $24(21-27)$ & 0.513 \\
\hline & $\begin{array}{l}\text { Post } 24 \\
\mathrm{~h}\end{array}$ & $21(19-24)$ & $21(19-25)$ & 0.883 \\
\hline \multicolumn{5}{|l|}{$\mathrm{Cr}$} \\
\hline & Preop & $0.8 \pm 0.2$ & $0.7 \pm 0.1$ & 0.059 \\
\hline & Post $1 \mathrm{~h}$ & $0.7(0.6-0.8)$ & $0.7(0.6-0.8)$ & 0.447 \\
\hline & $\begin{array}{l}\text { Post } 24 \\
\mathrm{~h}\end{array}$ & $0.7(0.6-1.0)$ & $0.7(0.6-0.8)$ & 0.166 \\
\hline
\end{tabular}

Values are expressed as the mean \pm standard deviation or median $(25 \%-75 \%)$. Abbreviations: Control, control group; RIPC, remote ischaemic preconditioning group; $\mathrm{CPK}$, creatinine phosphokinase; $\mathrm{LDH}$, lactate dehydrogenase; AST, aspartate aminotransferase; $\mathrm{Cr}$, creatinine; Preop, before anaesthesia induction; Post $1 \mathrm{~h}$, postoperative $1 \mathrm{~h}$; Post $24 \mathrm{~h}$, postoperative $24 \mathrm{~h}$.

Table 4. Serum cytokine level during total knee arthroplasty.

\begin{tabular}{|c|c|c|c|c|}
\hline & & Control $(\mathrm{N}=36)$ & $\operatorname{RIPC}(\mathrm{N}=36)$ & $P$ \\
\hline \multicolumn{5}{|l|}{ IL-6 } \\
\hline & Preop & $0.82(0.80-1.15)$ & $0.81(0.79-1.16)$ & 0.543 \\
\hline & End TQ & $0.81(0.79-1.11)$ & $0.87(0.79-1.18)$ & 0.328 \\
\hline & Post $1 \mathrm{~h}$ & $0.80(0.78-1.15)$ & $0.81(0.79-1.18)$ & 0.280 \\
\hline & Post $6 \mathrm{~h}$ & $0.82(0.80-1.06)$ & $0.83(0.80-1.17)$ & 0.287 \\
\hline & $\begin{array}{l}\text { Post } 24 \\
\text { h }\end{array}$ & $0.84(0.82-1.03)$ & $0.85(0.81-1.17)$ & 0.858 \\
\hline \multicolumn{5}{|c|}{ TNF-a } \\
\hline & Preop & $0.96(0.51-1.20)$ & $1.14(0.96-1.35)$ & 0.205 \\
\hline & End TQ & $0.92(0.45-1.25)$ & $1.10(0.58-1.56)$ & 0.231 \\
\hline & Post $1 \mathrm{~h}$ & $1.10(0.64-1.40)$ & $1.15(0.96-1.67)$ & 0.430 \\
\hline & Post $6 \mathrm{~h}$ & $1.04(0.59-1.25)$ & $1.06(0.76-1.62)$ & 0.468 \\
\hline & $\begin{array}{l}\text { Post } 24 \\
\mathrm{~h}\end{array}$ & 1.02 (0.51-1.17) & $1.05(0.62-1.58)$ & 0.451 \\
\hline \multicolumn{5}{|l|}{ IL-10 } \\
\hline & Preop & $13.42(8.67-15.71)$ & $10.71(7.94-18.88)$ & 0.783 \\
\hline & End TQ & $12.10(7.61-15.09)$ & $11.79(7.72-17.46)$ & 0.890 \\
\hline & Post $1 \mathrm{~h}$ & $12.72(8.14-15.04)$ & $10.99(7.68-15.24)$ & 0.709 \\
\hline & Post $6 \mathrm{~h}$ & $12.20(7.79-15.58)$ & $10.98(8.28-17.12)$ & 0.918 \\
\hline & $\begin{array}{l}\text { Post } 24 \\
\text { h }\end{array}$ & $12.06(8.28-15.17)$ & $10.70(8.09-19.90)$ & 0.613 \\
\hline \multicolumn{5}{|l|}{ TGF- $\beta$} \\
\hline & Preop & $1.42(1.05-2.23)$ & 1.47 (0.87-2.19) & 0.729 \\
\hline & End TQ & $0.90(0.67-1.96)$ & $0.92(0.52-1.19)$ & 0.607 \\
\hline & Post $1 \mathrm{~h}$ & $1.18(0.77-2.33)$ & 0.97 (0.41-1.47) & 0.160 \\
\hline & Post $6 \mathrm{~h}$ & $0.81(0.39-1.22)$ & $0.85(0.75-1.43)$ & 0.134 \\
\hline & $\begin{array}{l}\text { Post } 24 \\
\mathrm{~h}\end{array}$ & $0.99(0.58-1.21)$ & $0.68(0.42-0.99)$ & 0.097 \\
\hline
\end{tabular}

Values are expressed as median (25\%-75\%).

Abbreviations: Control, control group; RIPC, remote ischaemic preconditioning group; IL, interleukin; TNF- $\alpha$, tumour necrosis factor- $\alpha$; TGF- $\beta$, tumour growth factor- $\beta$; Preop, before anaesthesia induction; End TQ, just before release of tourniquet for operation site; Post $1 \mathrm{~h}$, postoperative $1 \mathrm{~h}$; Post $6 \mathrm{~h}$, postoperative $6 \mathrm{~h}$; Post $24 \mathrm{~h}$, postoperative $24 \mathrm{~h}$.
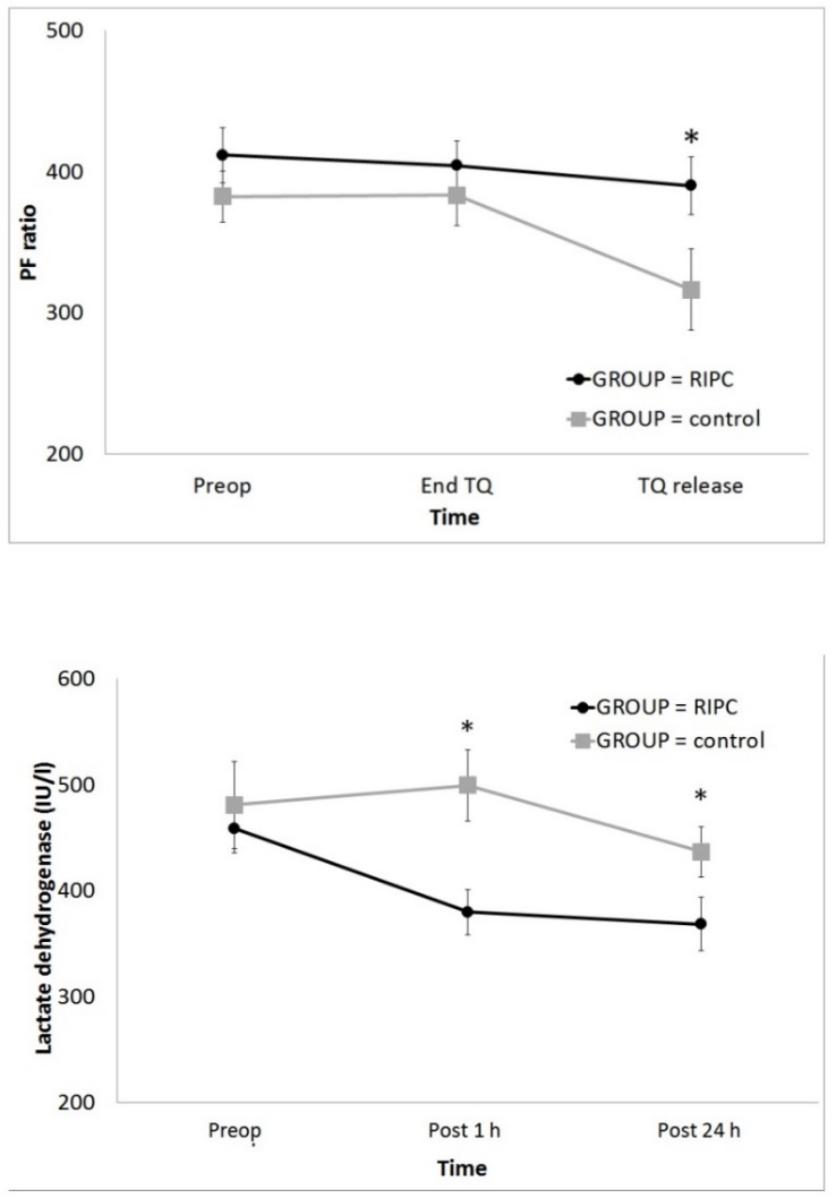

Figure 3. Change in the PF ratio and serum LDH level during total knee arthroplasty: (A) PF ratio and (B) LDH. Abbreviations: PF ratio, the ratio of the arterial oxygen partial pressure to the fractional inspired oxygen; LDH, lactate dehydrogenase; Preop, before anaesthesia induction; Pre $T Q$, just before the application of the tourniquet for the operation site; End TQ, just before the release of the tourniquet for the operation site; TQ release, just after the release of the tourniquet for the operation site; Post $1 \mathrm{~h}$, postoperative $1 \mathrm{~h}$; Post 24 h, postoperative 24 h. * Adjusted by Bonferroni's correction.

\section{Discussion}

The present study showed that RIPC ameliorated the regional cerebral oxygenation after tourniquet release during TKR. Additionally, pulmonary oxygenation was improved after RIPC during TKR. The total transfusion and bleeding amount up to $24 \mathrm{~h}$ postoperatively were significantly reduced by RIPC after TKR. Furthermore, RIPC was helpful in preventing serum LDH elevation after TKR.

We investigated cerebral oxygenation because decreased cerebral oxygenation represents cerebral hypoperfusion [17-19]. Although MBP showed a decreasing pattern after tourniquet release in both groups, the cerebral oxygenation did not decrease in the RIPC group after tourniquet release. We could assume several reasons for these results. First, an improved PF ratio after tourniquet release may contribute to preventing the deterioration of cerebral 
oxygenation because improved pulmonary oxygenation could have a beneficial effect on cerebral oxygenation. In general, inflammatory response induces pulmonary endothelial dysfunction and related hypoxia. However, ischaemic preconditioning minimises acute lung injury, neutrophil activation, and airway resistance, eventually improving pulmonary oxygenation in previous studies [10, 20-22]. Our study also showed that RIPC provided protection against worsening pulmonary oxygenation and improved the pulmonary oxygenation influence on cerebral oxygenation. Second, tourniquet release during TKR imposes a severe inflammatory reaction [3], and RIPC is known to have an anti-inflammatory effect [2, 23]. Therefore, the inflammation-related deterioration of cerebral oxygenation may be weakened due to the anti-inflammatory effect of RIPC. Finally, RIPC has the effect of reducing ischaemic reperfusion injury by nitric oxide release and related vasodilation release [24, 25]. Therefore, we could assume that released nitric oxide by RIPC in the present study may contribute to improving cerebral oxygenation.

In general, the ischaemic reperfusion injury reaction starts from tourniquet release; RIPC could have an effect after tourniquet release and during the postoperative period. Considering that the postoperative (not intraoperative) transfusion and bleeding amount were significantly lower in the RIPC group, we could presume that RIPC reduced the bleeding amount after TKR. The inflammatory response is known to impair normal haemostasis and increase the risk of bleeding [26]. However, the anti-inflammatory effect RIPC during TKR may attenuate the inflammatory reaction after tourniquet release, and the postoperative bleeding and related transfusion could be reduced in the present study. Additionally, regarding postoperative bleeding, we should observe the change in the LDH level after tourniquet release in the present study. The serum LDH level was significantly lower in the RIPC group than in the control group up to $24 \mathrm{~h}$ postoperatively. The LDH level is a representative factor of tissue damage, especially muscle damage [27]. Surgical injury and stress induce muscle damage and activate the inflammatory response. Therefore, we could assume that RIPC reduces the inflammatory response and related muscle damage; consequently, the serum LDH level could be lowered in the present study. Several previous studies have supported our assumption by showing that ischaemic preconditioning was helpful in reducing the serum LDH level [24, 25]. In addition, previous animal studies have revealed that cerebral hypoxia increases the serum LDH level [28-31]. Therefore, higher cerebral and pulmonary oxygenation after RIPC may also be additional contributing factors to the low serum LDH level in the present study.

The serum cytokine level did not show significant differences after RIPC application in the present study. Numerous studies have evaluated the change in the serum cytokine level after RIPC, but the results were not uniform. Cheung et al. revealed the beneficial effect of RIPC during cardiac surgery, although the serum cytokine level did not significantly change after RIPC [10]; they stated that the non-significant change of cytokine was related to the peak level of the postoperative cytokine reaction. Remote ischaemic preconditioning activates several immune pathways, such as neural and humoural pathways, and presents an organ protective effect [32]. Among these pathways, numerous immune responses can emerge during TKR; surgical stress itself could provide confounding factors that influence the change in the serum cytokine level. Thus, serum cytokine change may not be expressed as significantly in the present study. Additionally, RIPC should be preceded by an organ-specific ischaemic insult; however, there was only hypoperfusion after tourniquet release, without cerebral and pulmonary ischaemia in our study design. Likewise, the actual regional cerebral saturation was maintained within a normal range, even if it was higher in the RIPC group. Thus, significant changes in serum cytokine levels may not be expressed in our study. However, RIPC during TKR did provide clinical benefits, such as improved oxygenation and reduced bleeding.

Many elderly patients experience POCD after TKR under general anaesthesia [33, 34], and it is important because postoperative recovery is impaired by POCD $[35,36]$. There could be various factors that influence POCD and, especially, cerebral and pulmonary oxygenation could be a crucial cause [37]. Therefore, an adequate intraoperative oxygen supply for all vital organs such as the brain or lung is essential if postoperative complication is to be avoided. There was no POCD in the present study.

There were several considerations in the present study. We only evaluated cerebral oxygenation in the frontal lobe of the brain, and direct cerebral perfusion was not evaluated such as the middle cerebral artery blood flow, a good marker of global cerebral blood flow [17]. However, cerebral frontal lobe saturation could reflect cerebral blood flow and cerebral perfusion indirectly [19]. Furthermore, various studies for POCD [38, 39] did not evaluate the cerebral perfusion with inflammatory cytokine changes induced by tourniquet inflation and deflation during TKR. These novel data support the need for a larger study of RIPC in patients undergoing TKR. 
In conclusion, RIPC increased cerebral oxygenation after tourniquet release during TKR by improving pulmonary oxygenation. Additionally, RIPC decreased the transfusion and bleeding amount with the serum LDH level. RIPC is a safe, effective, and easy method to apply in clinical fields. Although RIPC showed some benefits, further experiments are clearly needed to establish the efficacy of RIPC during TKR.

\section{Acknowledgment}

This paper was written as part of Konkuk University's research support program for its faculty on sabbatical leave.

\section{Competing Interests}

The authors have declared that no competing interest exists.

\section{References}

1. Hooper G, Lee AJ, Rothwell A, Frampton C. Current trends and projections in the utilisation rates of hip and knee replacement in New Zealand from 2001 to 2026. N Z Med J. 2014; 127: 82-93.

2. Konstantinov IE, Arab S, Kharbanda RK, Li J, Cheung MM, Cherepanov V, et al. The remote ischemic preconditioning stimulus modifies inflammatory gene expression in humans. Physiol Genomics. 2004; 19: 143-50.

3. Cheng YJ, Chien CT, Chen CF. Oxidative stress in bilateral total knee replacement, under ischaemic tourniquet. J Bone Joint Surg Br. 2003; 85: 679-82.

4. Huh IY, Kim DY, Lee JH, Shin SJ, Cho YW, Park SE. Relation between preoperative autonomic function and blood pressure change after tourniquet deflation during total knee replacement arthroplasty. Korean J Anesthesiol. 2012; 62: 154-60.

5. Townsend HS, Goodman SB, Schurman DJ, Hackel A, Brock-Utne JG. Tourniquet release: systemic and metabolic effects. Acta Anaesthesiol Scand. 1996; 40: 1234-7.

6. Oxman T, Arad M, Klein R, Avazov N, Rabinowitz B. Limb ischemia preconditions the heart against reperfusion tachyarrhythmia. Am J Physiol. 1997; 273: H1707-12

7. McGrath BJ, Hsia J, Epstein B. Massive pulmonary embolism following tourniquet deflation. Anesthesiology. 1991; 74: 618-20

8. Pac-Soo $\mathrm{CK}$, Mathew $\mathrm{H}, \mathrm{Ma} \mathrm{D}$. Ischaemic conditioning strategies reduce ischaemia/reperfusion-induced organ injury. Br J Anaesth. 2014.

9. Przyklenk K, Bauer B, Ovize M, Kloner RA, Whittaker P. Regional ischemic 'preconditioning' protects remote virgin myocardium from subsequent sustained coronary occlusion. Circulation. 1993; 87: 893-9.

10. Cheung MM, Kharbanda RK, Konstantinov IE, Shimizu M, Frndova H, Li J, et al. Randomized controlled trial of the effects of remote ischemic preconditioning on children undergoing cardiac surgery: first clinical application in humans. J Am Coll Cardiol. 2006; 47: 2277-82

11. Veighey $K$, Macallister RJ. Clinical applications of remote ischemic preconditioning. Cardiol Res Pract. 2012; 2012: 620681.

12. Thielmann M, Kottenberg E, Kleinbongard P, Wendt D, Gedik N, Pasa S, et al. Cardioprotective and prognostic effects of remote ischaemic preconditioning in patients undergoing coronary artery bypass surgery: a single-centre randomised, double-blind, controlled trial. Lancet. 2013; 382: 597-604.

13. Hausenloy DJ, Mwamure PK, Venugopal V, Harris J, Barnard M, Grundy E, et al. Effect of remote ischaemic preconditioning on myocardial injury in patients undergoing coronary artery bypass graft surgery: a randomised controlled trial. Lancet. 2007; 370: 575-9.

14. Kharbanda RK, Mortensen UM, White PA, Kristiansen SB, Schmidt MR, Hoschtitzky JA, et al. Transient limb ischemia induces remote ischemic preconditioning in vivo. Circulation. 2002; 106: 2881-3.

15. Inouye $\mathrm{SK}$, van Dyck $\mathrm{CH}$, Alessi CA, Balkin S, Siegal AP, Horwitz RI Clarifying confusion: the confusion assessment method. A new method for detection of delirium. Ann Intern Med. 1990; 113: 941-8.

16. McNicoll L, Pisani MA, Ely EW, Gifford D, Inouye SK. Detection of delirium in the intensive care unit: comparison of confusion assessment method for the intensive care unit with confusion assessment method ratings. J Am Geriatr Soc. 2005; 53: 495-500.

17. Kay VL, Rickards CA. The role of cerebral oxygenation and regional cerebral blood flow on tolerance to central hypovolemia. Am J Physiol Regul Integr Comp Physiol. 2016; 310: 16.
18. Lewis NC, Bain AR, MacLeod DB, Wildfong KW, Smith KJ, Willie CK, et al. Impact of hypocapnia and cerebral perfusion on orthostatic tolerance. J Physiol. 2014; 592: 5203-19.

19. Madsen PL, Secher NH. Near-infrared oximetry of the brain. Progress in Neurobiology. 1999; 58: 541-60.

20. Avgerinos ED, Kostopanagiotou G, Costopanagiotou C, Kopanakis N, Andreadou I, Lekka $\mathrm{M}$, et al. Intestinal preconditioning ameliorates ischemia-reperfusion induced acute lung injury in rats: an experimental study. J Surg Res. 2010; 160: 294-301

21. Harkin DW, Barros D'Sa AA, McCallion K, Hoper M, Campbell FC. Ischemic preconditioning before lower limb ischemia--reperfusion protects against acute lung injury. J Vasc Surg. 2002; 35: 1264-73.

22. Li G, Chen S, Lu E, Luo W. Cardiac ischemic preconditioning improves lung preservation in valve replacement operations. Ann Thorac Surg. 2001; 71: $631-5$

23. Tamion F, Richard V, Lacoume Y, Thuillez C. Intestinal preconditioning prevents systemic inflammatory response in hemorrhagic shock. Role of HO-1. Am J Physiol Gastrointest Liver Physiol. 2002; 283: G408-14.

24. de Oca J, Hotter G, Sola A, Gonzalez R, Rafecas A, Rosello J, et al. Role of nitric oxide in preconditioning for intestinal transplantation. Transplant Proc. 1999; 31

25. Hotter G, Closa D, Prados M, Fernandez-Cruz L, Prats N, Gelpi E, et al. Intestinal preconditioning is mediated by a transient increase in nitric oxide. Biochem Biophys Res Commun. 1996; 222: 27-32.

26. Laffey JG, Boylan JF, Cheng DC. The systemic inflammatory response to cardiac surgery: implications for the anesthesiologist. Anesthesiology. 2002; 97: $215-52$

27. Koulmann N, Richard-Bulteau H, Crassous B, Serrurier B, Pasdeloup M, Bigard X, et al. Physical exercise during muscle regeneration improves recovery of the slow/oxidative phenotype. Muscle Nerve. 2016; 22: 25151.

28. Koudelova J, Rauchova H, Vokurkova M. Activity of lactate dehydrogenase in serum and cerebral cortex of immature and mature rats after hypobaric hypoxia. Neurochem Res. 2006; 31: 915-9.

29. Trojan S, Langmeier M, Maresova D, Pokorny J. Dehydrogenase activity in the blood and brain after adaptation to intermittent hypoxia. Sb Lek. 2000; 101: $11-6$.

30. Tskitishvili E, Pequeux C, Munaut C, Viellevoye R, Nisolle M, Noel A, et al. Use of Estetrol with other Steroids for Attenuation of Neonatal Hypoxic-Ischemic brain injury: to combine or not to combine? Oncotarget. 2016; 25.

31. Ramljak S, Schmitz M, Zafar S, Wrede A, Schenkel S, Asif AR, et al. Regular Article: Cellular prion protein directly interacts with and enhances lactate dehydrogenase expression under hypoxic conditions. Experimental Neurology. 2015; 271: 155-67.

32. Costa JF, Fontes-Carvalho R, Leite-Moreira AF. Myocardial remote ischemic preconditioning: from pathophysiology to clinical application. Rev Port Cardiol. 2013; 32: 893-904.

33. Scott JE, Mathias JL, Kneebone AC. Postoperative Cognitive Dysfunction after Total Joint Arthroplasty in the Elderly: A Meta-Analysis. The Journal of Arthroplasty. 2014; 29: 261-7.e1

34. Newman S, Stygall J, Hirani S, Shaefi S, Maze M. Postoperative cognitive dysfunction after noncardiac surgery: a systematic review. Anesthesiology. 2007; 106: 572-90.

35. Rundshagen I. Postoperative cognitive dysfunction. Dtsch Arztebl Int. 2014; 111: $119-25$

36. Rudolph JL, Marcantonio ER. Review articles: postoperative delirium: acute change with long-term implications. Anesth Analg. 2011; 112: 1202-11.

37. Zywiel MG, Prabhu A, Perruccio AV, Gandhi R. The influence of anesthesia and pain management on cognitive dysfunction after joint arthroplasty: a systematic review. Clin Orthop Relat Res. 2014; 472: 1453-66.

38. Reichenberg A, Yirmiya R, Schuld A, Kraus T, Haack M, Morag A, et al. Cytokine-associated emotional and cognitive disturbances in humans. Arch Gen Psychiatry. 2001; 58: 445-52.

39. Peng L, Xu L, Ouyang W. Role of peripheral inflammatory markers in postoperative cognitive dysfunction (POCD): a meta-analysis. PLoS One. 2013; 8: e79624. 